
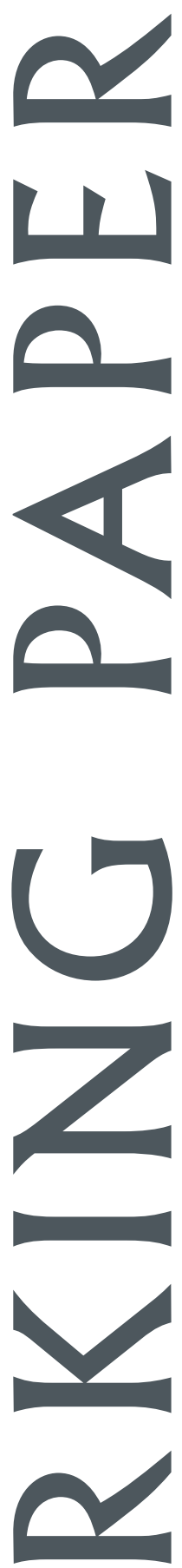

EAST-WEST CENTER 
The U.S. Congress established the East-West Center in 1960 to foster mutual understanding and cooperation among the governments and peoples of the Asia Pacific region including the United States. Funding for the Center comes from the U.S. government with additional support provided by private agencies, individuals, corporations, and Asian and Pacific governments.

East-West Center Working Papers are circulated for comment and to inform interested colleagues about work in progress at the Center.

For more information about the Center or to order publications, contact:

Publication Sales Office

East-West Center

1601 East-West Road

Honolulu, Hawaii 96848-1601

Telephone: 808-944-7145

Facsimile: 808-944-7376

Email: ewcbooks@EastWestCenter.org

Website: www.EastWestCenter.org 


\title{
Interregional Burden-Sharing of Greenhouse Gas Mitigation in the United States
}

\author{
Adam Rose and ZhongXiang Zhang
}

Adam Rose is a Professor of Energy, Environmental, and Regional Economics in the Department of Geography at the Pennsylvania State University, where he previously served as Professor and Head of the Department of Energy, Environmental, and Mineral Economics. He is the author of several books and more than 100 papers on the subjects of energy, environmental, and regional economics, economic development, and the economics of natural hazards. Professor Rose serves on the editorial boards of the Journal of Regional Science, Resource and Energy Economics, Energy Policy, Resource Policy, and Pacific and Asian Journal of Energy. He received a Ph.D. in economics from Cornell University.

ZhongXiang Zhang is a Fellow in the Research Program at the East-West Center. He is also an adjunct professor of economics at both the Chinese Academy of Social Sciences and Peking University, Beijing, and an affiliate professor of economics at the University of Hawaii at Manoa. As the author of more than 120 publications in the fields of energy, climate and environmental economics, trade and the environment, public finance and macroeconomic modelling, he wrote the book The Economics of Energy Policy in China: Implications for Global Climate Change (Edward Elgar, 1998) and co-authored International Rules for Greenhouse Gas Emissions Trading (United Nations, 1999). Currently, Dr. Zhang serves on the editorial boards of seven international journals and one Chinese journal.

East-West Center Working Papers: Environmental Change, Vulnerability, and Governance Series is an unreviewed and unedited prepublication series reporting on research in progress. The views expressed are those of the authors and not necessarily those of the Center. Please direct orders and requests to the East-West Center's Publication Sales Office. The price for Working Papers is $\$ 3.00$ each plus shipping and handling. 
INTERREGIONAL BURDEN-SHARING OF GREENHOUSE GAS MITIGATION

\title{
IN THE UNITED STATES
}

by

\author{
Adam Rose \\ Department of Geography \\ The Pennsylvania State University \\ 213 Walker Building \\ University Park, PA 16802 \\ United States \\ Tel: +1 814 863-0179 \\ Fax: +1 814 863-7943 \\ E-mail: azr1@psu.edu \\ and \\ ZhongXiang Zhang \\ Research Program \\ East-West Center \\ 1601 East-West Road \\ Honolulu, HI 96848-1601 \\ United States \\ Tel: +1 808 944-7265 \\ Fax: +1 808 944-7298 \\ Email: ZhangZ@EastWestCenter.org
}




\title{
INTERREGIONAL BURDEN-SHARING OF GREENHOUSE GAS MITIGATION IN THE UNITED STATES
}

\author{
Adam Rose $^{\mathrm{a}}$ and ZhongXiang Zhang ${ }^{\mathrm{b}}$ \\ ${ }^{a}$ Professor, Department of Geography, The Pennsylvania State University, \\ 213 Walker Building, University Park, PA 16802 \\ (*Author for correspondence: Fax: 814-863-7943; E-mail: azr1@psu.edu) \\ ${ }^{\mathrm{b}}$ Senior Economist, Research Program, East-West Center, \\ 1601 East-West Road, Honolulu, HI 96848-1601
}

\begin{abstract}
Emissions trading is an attractive candidate for implementing greenhouse gas mitigation, because it can promote both efficiency and equity. This paper analyzes the interregional impacts of alternative allocations of carbon dioxide emission permits within the U.S. The analysis is performed with the aid of a nonlinear programming model for ten EPA Regions and for six alternative permit distribution formulas. The reason that various alternatives need to be considered is that there is no universal consensus on the best definition of equity. Advance knowledge of absolute and relative regional economic impacts provides policy-makers with a stronger basis for making the choice.

The analysis yields several useful results. First, the simulations indicate that no matter how permits are allocated, this policy instrument can substantially reduce the cost of greenhouse gas mitigation for the U.S. in comparison to a system of fixed quotas for each of its regions. Interestingly, the welfare impacts of several of the allocation formulas differ only slightly despite the large differences in their philosophical underpinnings. Also, the results for some equity criteria differ greatly from their application in the international domain. For example, the Egalitarian (per capita) criterion results in the relatively greatest cost burden being incurred by one of the regions of the U.S. with the lowest per capita income.
\end{abstract}

Keywords: tradeable emission permits, climate policy, interregional equity

JEL classification: Q54; Q58; Q52; Q48 


\section{INTRODUCTION}

The success of emissions trading in lowering the cost of compliance with acid rain legislation (Ellerman et al., 2000) makes this policy instrument an attractive candidate for implementing greenhouse gas mitigation within the U.S. (Rose and Oladosu, 2002). In addition to its ability to promote economic efficiency by rewarding the least-cost mitigation options, a tradeable permit approach also has the ability to promote equity (Rose, 1992) or environmental justice (Solomon and Lee, 2000). This is important in its own right from a normative standpoint, but also from a pragmatic standpoint of facilitating an agreement where voluntary cooperation or a political consensus is needed. Nations as parties to a global agreement, or regions and individual emitters within a nation when implementation reaches that stage, are unlikely to be convinced of the worthiness of a policy solely on the basis of an abstract goal such as overall efficiency, from which their individual well-being is derivative. ${ }^{1}$ They are more likely to be favorably disposed toward a policy that explicitly considers their own welfare and its relation to others (Rose and Stevens, 1998; Zhang, 2000a, 2001). Features of the tradeable permit instrument enable policymakers to address international or interregional equity head on, and in a manner that does not undercut efficiency, through the initial permit distribution (Rose et al., 1998). ${ }^{2}$

This paper analyzes the interregional economic impacts of alternative allocations of carbon dioxide emission permits within the U.S. in conformance with the Kyoto Protocol commitment to reduce emissions by 7\% below 1990 baseline levels in the Year 2010. ${ }^{3,4}$ The analysis is performed for ten EPA Regions and for six alternative permit distribution principles. The reason that various alternatives need to be considered is that there is no universal consensus on the best definition of equity. Advance knowledge of absolute and relative regional economic impacts provides policy-makers with a stronger basis for making the choice.

The analysis is performed with a non-linear programming model previously applied to international greenhouse gas permit trading (Zhang, 2000a). The simulations estimate mitigation cost impacts before and after permit trading, as well as the market-clearing permit price. We also simulate the workings of the market at a fixed permit price of $\$ 20$ per ton of carbon, often presented as a maximum tolerable level for the U.S. cooperation. The six equity criteria are applied here to the politically favored approach of "grandfathering" (free granting) of permits, as opposed to auctioning (federal government selling) them, though the methodology is sufficiently general to analyze the latter. Simulations are performed for a single trading period, though the analysis can be extended over a longer time horizon and with intertemporal features (banking and borrowing of emissions) in a manner similar to the analysis of international permit trading by Stevens and Rose (2002). 


\section{PERMIT ALLOCATIONS}

Several alternative equity criteria have been put forth for the interregional (Rose and Webber, 1992) and international (Rose et al., 1998) analysis of the equity implications of environmental policy. Nine equity principles, a general operational rule emanating from each, and a corresponding rule applicable to the allocation of tradeable permits at the regional level are presented in Table I.

Of course, there are other levels of application of equity criteria, including sectors and households (see, e.g., Kopp et al., 1999). In some ways, these units are superior to regions, because they address the issue of relative impacts in terms of welfare of the individual (the basic unit in a democracy). Two reasons are offered for orienting the analysis to the regional level, however. First, are limitations on the availability of data for production and household delineations according to welfare levels (e.g., income brackets or profit rates). Second, political realities indicate that regions are important. This is reinforced by the "regional" character of Congress and several major economic sectors (e.g., oil and gas production, steel), which have translated into "regional influence" in previous environmental policy-making, such as U.S. acid rain legislation. Several other important regional dimensions of the issue relating to natural and social science considerations are discussed in Easterling (1997), Easterling et al. (1998), and Solomon and Lee (2000).

The six permit allocation formulas (consisting of an equity criterion and an associated "reference base") simulated in this paper are: ${ }^{5}$

1. Sovereignty (emissions based)

2. Egalitarian (population based)

3. Economic Activity (GRP based)

4. Ability to Pay (inverse-GRP based)

5. Sovereignty (energy-use based)

6. Sovereignty (energy-production based)

A reference base is essentially a metric or index against which to apply an equity criterion and itself has no ethical content (Rose, 1992; Rose and Stevens, 1998). ${ }^{6}$ Moreover, there is not a one-to-one correspondence between criteria and reference bases. For example, the Sovereignty criterion can be implemented according to more than one reference base, and Gross Regional Product (GRP) can serve as a reference base for more than one criterion. ${ }^{7}$ Reference base distinctions are, however, very important. For example, criterion 5 simulates a "downstream" administered program on fossil energy end-users, while criterion 6 simulates an "upstream" program on fossil energy producers. ${ }^{8}$ Moreover, the welfare implications of various references bases for a given equity criterion will differ as well.

Permit allocations for the ten U.S. regions according to the six formulas are presented in Table II. ${ }^{9}$ Note that two sets of numbers are presented for several formulas. The numbers in parentheses are the unadjusted number of permits, which are considered untenable because they exceed gross emissions in the Year 2010 for some regions. Such surplus permits for developing countries have proponents in the international domain, where some analysts and policy makers view a climate 
change treaty as a means for redressing international disparities in income. At first glance, no region in the U.S. is likely to be viewed in the same light as requiring especially large transfers. Under the Sovereignty (emissions based) formula, however, New England would be slated to receive a surplus because its projected 2010 emissions are significantly lower than its Year 1990 emissions, so that even a 5\% cutback of 1990 emissions would allow that region to emit more than its Year 2010 level. Some would suggest that excess permits could be justified as a reward for a downward emission path attained even without pressure from the Kyoto Protocol. The counter-argument is that the downward emissions trend in New England is not so much of a concerted effort but more of a matter of

continued economic decline in that region. ${ }^{10}$ Of course, this is likely to be further countered by the suggestion that a lagging economy warrants excess permits. ${ }^{11}$

The excess permits are even more problematic in the unadjusted columns of the Egalitarian, Economic Activity, Ability to Pay, and Sovereignty (energy-production based) criteria.

Accordingly, for these simulations, the permits have been capped at Year 2010 levels, and the equity principles have been applied to the remaining regions. This mutes the difference between allocation rules significantly (compare the unadjusted sets and the adjusted sets). However, some prominent differences still remain (see, e.g., the adjusted permit allocations for the South East, North Central, and South Central States under the Egalitarian criterion). Other peculiarities in permit allocations will be discussed below.

\section{THE MODEL}

Our model is based on well-established principles of the ability of unrestricted permit trading to achieve a cost-effective allocation of resources in the presence of externalities (see, e.g., Tietenberg, 1985). In the context of the Kyoto Protocol, where a strict cap implies unique GHG emission reduction requirements, the individual region and overall national optimization can be accomplished without explicit consideration of the benefits side of the ledger (i.e., it yields "efficiency without optimality"). Therefore, the model simply requires equalization of marginal costs of all entities with the equilibrium permit price. This ensures minimization of total net compliance costs for each region and minimization of total abatement costs for the nation as a whole (see also Stevens and Rose, 2002). For purchasing regions, compliance costs are equal to own abatement cost plus the cost of permits, whereas for selling regions, compliance costs are equal to own abatement cost minus the revenues from selling permits. For the nation as a whole, permit sales and purchases cancel out, simplifying the overall objective functions.

We assume that the marginal abatement cost function for region $i$ is of the logarithmic form, similar to Nordhaus $(1991,1994):^{12}$

$$
M C A_{i}=-\ln \left(1-R_{i}\right) / \alpha_{i} \quad i=1, \ldots, n
$$

where $M C A_{i}$ is the marginal cost of abatement for region $i, R_{i}$ is the percentage of greenhouse gas abatement undertaken by region $i$ in million tons of carbon, and $\alpha_{i}$ is a cost parameter. This functional form has the desired property of positive and increasing marginal cost for $\alpha>0 .{ }^{13}$ This cost parameter also captures technological and other distinctions that cause mitigation costs to differ across regions. By integration, the total cost of abatement for region $i, T C A_{i}$, is: 


$$
T C A_{i}=\int_{0}^{R_{i}}\left[\left(-\ln \left(1-r_{i}\right) / \alpha_{i}\right) d r_{i} E_{i}\right]=\left[\frac{\left(1-R_{i}\right) \cdot \ln \left(1-R_{i}\right)+R_{i}}{\alpha_{i}}\right] \cdot E_{i} \quad i=1, \ldots, n
$$

where $E_{i}$ is each region's gross (unabated) emissions in million tons of carbon. Denoting the total required percentage reduction of emissions in region $i$ in the absence of emissions trading as $\bar{R}_{i}$, the total abatement cost for each region in the absence of trading, $T C \bar{R}_{i}$, is calculated as:

$$
T C \bar{R}_{i}=\int_{0}^{\bar{R}_{i}}\left[\left(-\ln \left(1-r_{i}\right) / \alpha_{i}\right) d r_{i} E_{i}\right]=\left[\frac{\left(1-\bar{R}_{i}\right) \cdot \ln \left(1-\bar{R}_{i}\right)+\bar{R}_{i}}{\alpha_{i}}\right] \cdot E_{i} \quad i=1, \ldots, n
$$

Emissions trading helps a region with relatively high marginal abatement cost to lower its compliance cost by avoiding the undertaking of autarkic actions. To minimize compliance costs, a purchasing region undertakes only some of its abatement requirement itself, $R_{i} E_{i},\left(R_{i} E_{i}<\bar{R}_{i} E_{i}\right)$, up to the point where the marginal cost of doing so is equal to the endogenously determined permit price, $P$ :

$$
-\ln \left(1-R_{i}\right) / \alpha=M C A_{i}=P \quad i \in N
$$

where $N$ is the set of all regions.

The region meets the remaining demand, $\left(\bar{R}_{i} E_{i}-R_{i} E_{i}\right)$, via purchasing the "right to emit" at the national market price, $P$. So, the total remaining demand for emission permits of all purchasing regions, $T D$, is:

$$
T D=\sum_{i}\left(\bar{R}_{i} E_{i}-R_{i} E_{i}\right) \quad i \in N
$$

On the other hand, for the region $j$ with relatively low marginal cost, emissions trading provides it an incentive to undertake abatement and sell permits to those higher-cost regions at the equilibrium permit price, $P$ :

$$
-\ln \left(1-R_{i}\right) / \alpha_{i}=M C A_{i}=P \quad j \in N
$$


Thus, the total amount of emissions permits available for sale, TS, is:

$$
T S=\sum_{j}\left(R_{j} E_{j}-\bar{R}_{j} E_{j}\right) \quad j \in N
$$

The sum of total number of purchasing regions $i$ and total number of selling regions $j$ will be equal to $n$. At the equilibrium, the total demand for emissions permits is equal to the total supply:

$$
T S=T D
$$

Substituting Eq. (5) and Eq. (7) into Eq. (8) and rearranging yields the condition that the total emissions actually abated equal the total emission abatement requirement:

$$
\sum_{i} R_{i} E_{i}=\sum_{i} \bar{R}_{i} E_{i} \quad i=1, \ldots, n
$$

We solve the model by minimizing total abatement costs of all regions $\sum_{i} T C A_{i}$ subject to Eq. (4) through Eq. (8), using GAMS, an algebraic modeling system for linear, nonlinear, and integer programming problems (Brooke et al., 1996). ${ }^{14}$ The solution yields the equilibrium permit price $(P)$, each region's own abatement after trading $\left(R_{i} E_{i}\right)$, and each region's marginal abatement cost $\left(M C A_{i}\right)$. Because we focus on unrestricted emissions trading, ${ }^{15}$ in equilibrium the marginal cost of abatement for each region is the same and is equal to the permit price, indicated in Eq. (4) and Eq. (6).

This completes the description of the general model by which the permit price, $M C A_{i}$, and $R_{i} E_{i}$ are determined endogenously. In the case where the permit price is set exogenously, the situation becomes much simpler because $M C A_{i}$ and hence $R_{i} E_{i}$ follows suit. There is no need for Eqs. (5), (7), (8), and (9) because the total sales of selling regions to purchasing regions are not equal to the total purchases, except by chance (when the specified permit price equals the equilibrium price). In the likely case where the permit price is lower than the equilibrium price, it is assumed that the federal government will provide any shortfalls at the exogenously set permit price.

\section{SIMULATION RESULTS}

Our simulations were performed with the model presented in the previous section calibrated to the abatement cost functions for each of the ten EPA Regions. The empirical base of the model is an extension of that developed by Rose and Stevens (1993) and Stevens and Rose (2002). The major refinement in this present study was to specify mitigation cost functions for each of the ten U.S. regions. This was done by adjusting the U.S. mitigation cost function in the Rose-Stevens model by parametric shifts for the ten regions in direct proportion to their energy intensity weighted by the relative carbon content of the three major fossil fuels. ${ }^{16}$ Thus, higher cost regions are the South Central and North Central States, with relatively lower cost regions being 
New England, New York/New Jersey and South West States. This is an admittedly crude basis for mitigation cost specifications, and hence the results presented here should be taken only as generally illustrative of the issues at hand. ${ }^{17}$

The results of selected simulations are presented in Tables III through VIII. Two simulations were performed for each equity criterion:

a. Simulation 1 requires that U.S. emissions in the Year 2010 for the country as a whole be $5 \%$ below its 1990 baseline level. Based on our model, the associated (endogenously determined) price of permits is estimated to be $\$ 25.25 / \mathrm{tC}$.

b. Instead of setting an overall reduction target like Simulation 1, Simulation 2 caps the permit price at $\$ 20 / \mathrm{tC} .{ }^{18}$ According to our calculations, the imposition of this permit price leads to a (endogenously determined) 3.3\% reduction of 1990 baseline carbon emissions.

Note that the $5 \%$ reduction requirement is lower than the $7 \%$ U.S. commitment to the Kyoto Protocol because previous simulations indicate that it would be optimal for the U.S. to purchase permits equal to $2 \%$ of its 1990 baseline emissions in an international permits market (Rose and Stevens, 1998). Of course, our methodology is sufficiently general to analyze all alternative levels of mitigation; moreover, the qualitative nature of the results, in terms of relative regional impacts, of a full $7 \%$ reduction are not likely to differ much from those presented here. ${ }^{19}$

The regional cost impact of the Sovereignty (emissions-based) formula for the Year 2010 for the case of a 5\% reduction of 1990 baseline emissions (total U.S. permits equivalent to $95 \%$ of 1990 baseline) are represented in Table IIIA both before and after permit trading. Before trading, total mitigation costs are $\$ 2.47$ billion, and two of the regions incur no mitigation costs because their permits holdings are equivalent to Year 2010 emissions. After trading, total mitigation costs are reduced to $\$ 1.46$ billion, or a savings of approximately $40 \%$, by shifting mitigation to the lower cost options (regions). Five regions (South East, North Central, South Central, Plains, Mountains) purchased a total of $\$ 1.11$ billion of permits from four selling regions (New England, New York/New Jersey, Mid-Atlantic, South West States). The North West does not engage in any significant permit trading because its mitigation costs are at the U.S. weighted average. Note that all regions are better off as a result of permit trading, with each entry of the Net Cost column after trading being lower than the corresponding element in the Net Cost column before trading. Interestingly, four of the regions are able to sell such a sizeable amount of permits that their costs of compliance are in fact negative. There are permit allocation rules that can prevent such an outcome, if it is deemed undesirable, by channeling net gains back to regions whose net costs are positive (see the Compensation criterion in Table I). ${ }^{20}$

The results of the capped permit price of $\$ 20.00 / \mathrm{tC}$ are presented in Table IIIB, and correspond to an overall emission reduction of 3.3\%, or about one-third lower than in Table IIIA. Individual region and total mitigation costs before trading and after trading are also about onethird lower as well. ${ }^{21}$ Qualitatively (i.e., in terms of positive or negative sign), the Net Cost results in Table IIIB are the same as in Table IIIA for the individual regions, though the proportional reduction in permit revenues and expenditures vary somewhat. 
The results for the Egalitarian criterion are presented in Tables IVA and IVB. Since the permit assignments are more skewed than in the Sovereignty case, ${ }^{22}$ the total costs before trading are much higher-- $\$ 10.73$ billion. However, after trading, the total costs are $\$ 1.46$ billion, the same as in Table IIIA. This is a verification of the Coase Theorem, which stipulates that efficiency will be attained irrespective of the initial distribution of permits. Moreover, given convexity properties of the analysis, the efficiency level is unique, as indicated by the identical individual and total mitigation costs figures in the "After Trading" mitigation cost columns. ${ }^{23}$ The total net cost is also the same in Tables IIIA and IVA (and IIIB and IVB), but individual net cost figures differ because permit revenue and expenditures are directly related to the distribution of permits. The dramatic result is the adverse impact on the South Central States. This Region has the highest $\mathrm{CO}_{2}$ emission rate per person and the highest mitigation cost curve, which combine to give it a mitigation cost before trading of $\$ 9.84$ billion, nearly $90 \%$ of the U.S. total. Trading brings the mitigation costs down dramatically to $\$ 0.16$ billion but at the expense of buying $\$ 2.09$ billion of permits. The net cost result of $\$ 2.26$ billion is higher than the U.S. total, indicating that this Region alone practically subsidizes $\mathrm{CO}_{2}$ emission control for most of the rest of the U.S. The individual region and total results are qualitatively the same in Table IVB as in IVA, but smaller in value because of the lower mitigation requirement.

The results of grandfathering $\mathrm{CO}_{2}$ emission permits according to Economic Activity as measured by a Gross Regional Product (GRP) reference base are presented in Table V for the 5\% reduction case. Note from Table II that this allocation formula differs philosophically from criteria 1, 2, and 4, which are basically altruistic in nature. This formula, as well as formulas 5 and 6, gives a greater proportion of permits to those regions with higher economic activity and higher levels of energy production or use. In effect, they endorse the status quo with respect to emissions (some consider it fair to "maintain the lifestyle to which people are accustomed"). Note the GRP criterion does not necessarily give the greatest share of permits to the wealthiest region, because it is not implemented in terms of GRP per capita (it would be difficult to justify such a measure in any case). The results in Table $\mathrm{V}$ are very similar to results in Table IVA, with the South Central States undertaking the lion's share of mitigation before trading and purchasing the lion's share of permits. The final welfare effects for individual regions are almost identical between the two tables. In essence, this reflects the high correlation between population and economic activity in the U.S. (again quite a contrast to the international scene). ${ }^{24}$ In the international context, the fact that poorer countries have higher populations gives them a very large portion of permits, thereby resulting in very large transfers from industrialized countries. In the U.S. case, such transfers from relatively rich to poor regions are rather meager and, in the Egalitarian and Economic Activity formula cases, somewhat perverse from the standpoint of altruism, since the South Central Region, the second poorest region in per capita GRP terms, incurs by far the greatest cost burden.

The results of the Ability to Pay criterion are presented in Table VI. Here the permits are grandfathered on the basis of inverse GRP per capita, so that poorer regions receive the larger share of permits. The unadjusted permit distribution (see the figures in parentheses in Table II) are the most even of any of the criteria, but the "no excess permit" cap reallocates them significantly. Before trading, the entire mitigation cost burden falls on the North Central and South Central States, and hence these are the only two regions that purchase permits. After 
trading, these are the only two regions that incur positive costs, though the amount for the South Central States is significantly lower for this simulation than in the two previous simulations.

The two energy-related, Sovereignty-based formulas simulations contrast cases of downstream and upstream applications of mitigation policy. The results for the Sovereignty Energy-Use case are presented in Table VII. Note that these are based on an allocation that bears a closer resemblance to the emissions-based Sovereignty formulas than any of the others (see again Table II). The "Before Trading" total emission control costs are the lowest for any of the cases, meaning this initial allocation is closest to the efficient outcome of any of the six alternatives simulated here. Also, each region is assigned fewer permits than its Year 2010 projected level, so each would have to incur some mitigation costs in the absence of trading, with the South East and South Central States in the lead. These two regions plus the Mid-Atlantic, Plains, and Mountain States would be permit buyers, and the remaining States would be permit sellers. However, eight of the ten Regions would incur net costs after trading, the lone exceptions being New York/New Jersey and the North West States, but only by trivial amounts.

The results of the Sovereignty Energy Production ("upstream" application) case are presented in Table VIII. This allocation is dramatically different than all the others because of the near-zero basis for New England, which produces almost no fossil fuels. We thus drop this region out and shift the mitigation burden to the other regions. Because we have removed one of the lower mitigation cost options (New England), the "After Trading" total cost in Table VIII is higher than all of the other simulations, and the equilibrium permit rises to more than $\$ 27 / \mathrm{tC}$. Note also the perverse nature of the outcome for this situation, since higher fossil fuel producing regions receive a higher proportion of the allowances. Thus, the South Central States are not required to undertake any mitigation, and the cost burden is shifted to regions that produce the least fossil energy, primarily New York/New Jersey. (A similar, but less obvious shift takes place for the energy-use based version of the Sovereignty criterion presented in Table VII.) This points to problems associated with formulas that effectively perpetuate the status quo, especially those that "grandfather" the negative aspect of the problem. An alternative is to make mitigation requirements directly proportional to fossil energy production, rather than the obverse of granting allowances on this basis. This would reverse the results across regions in Table VIII. At the same time, this alternative is not unequivocally reasonable. It raises the important issue of the "responsibility" for emissions. Should fossil fuel producing regions be blamed for the global warming problem or is it the responsibility of the using regions? Again, this is an issue that has perplexed the international discussion of greenhouse gas emissions trading for many years.

To facilitate comparison, the net cost results for each of the formulas simulated are presented in Table IX. In addition some key considerations for selected regions are illustrated in Figures 1 and 2. Figure 1 shows vividly that the criterion for permit allocation matters little for regions such as New England, South West, and Mid-Atlantic States, while it matters greatly for regions such as the South Central and North Central States. As illustrated in Figure 2, net costs of GHG mitigation track closely with permit allocations. ${ }^{25}$

\section{CONCLUSION}


We have simulated the interrregional cost impacts of several equity formulas (criteria plus reference bases) for grandfathering carbon dioxide emission permits. Two criteria are based on altruistic concepts of equity, while four are various forms of proportional adjustment to the status quo. Making the permits tradeable reduces the cost in all cases, and in some by as much as nearly $90 \%$. While initial allocations across regions vary substantially among most criteria, trading also greatly helps reduce the disparities and outcomes across most of them.

The analysis sheds light on major aspects of policy design currently subject to much debate, such as emission permit allocations and their upstream vs. downstream application. It also reveals several ironies and idiosyncrasies regarding a system of tradeable $\mathrm{CO}_{2}$ permits within the U.S., such as the possibility of granting excess permits to several regions under most of the formulas, and the strong positive correlation between some reference bases (GRP and population), not found in the international context, and which results in a relatively small amount of interregional transfers and the highest burden-sharing by one of the least well-off regions.

We emphasize that our results are based on some heroic assumptions concerning regional mitigation cost differentials. However, our analysis should provide a useful methodology and insights into several important features of a system of tradeable greenhouse gas emission permits, as well as major policy issues surrounding sharing the cost burden across regions of the U.S. 


\section{ENDNOTES}

- The authors are, respectively, Professor, Department of Geography, The Pennsylvania State University, University Park, PA 16802; and Senior Economist, Research Program, East-West Center, 1601 East-West Road, Honolulu, HI 96848-1601. The authors are grateful to Shu-Yi Liao for his assistance in collecting the data and in performing the computer simulations, and to Madhu Khanna and three anonymous reviewers for their helpful comments.

${ }^{1}$ That is, economic efficiency can be attained irrespective of the welfare impacts on the various parties. In many cases, the efficient outcome results in great disparities in these impacts.

${ }^{2}$ The ability of the property rights solution to achieve an efficient allocation of resources in the presence of an externality was first articulated by Coase (1960). He emphasized that under ideal conditions the efficient outcome would take place irrespective of how the property rights (in this case, permits) were initially distributed. He reasoned that any distribution of permits that did not result in significant income effects or transactions costs would achieve efficiency because of the workings of the new market being established. This has often been taken to imply that both the equity implications of the initial distribution and of the welfare outcome are of secondary importance. This is clearly not the case in burden sharing of greenhouse mitigation, where voluntary cooperation or political consensus is needed. Ironically, the Coase Theorem actually provides a justification for fine-tuning equity in this context. If an efficient allocation can be attained irrespective of how property are distributed, then the manipulation of permit assignments in order to entice more parties to enter into agreement will not undercut efficiency. Thus, the efficiencyequity tradeoff, which is often present and often used as a justification for ignoring equity, is not pertinent in this case.

${ }^{3}$ Note that at the time of the writing of this paper, the Bush Administration is on record against U.S. ratification of the Kyoto Agreement. However, the fifteen member nations of the European Union have just ratified the Agreement, and international pressure is mounting on the U.S. Several states and cities in the U.S. have established targets and timetables for GHG reduction. The New England Governor's Association, in conjunction with the Canadian maritime Provinces, have not only set targets but also outlined plans for an emissions trading system to achieve them (CCAP 2002). Even Bush's alternatives have some features of the Kyoto Protocol, including emission reduction targets. Moreover, the U.S. has been the leader in promoting emission permits or other "flexibility mechanisms" in the implementation of Kyoto. Thus, the analysis in this paper is still very pertinent to future climate negotiations both at the international and interregional levels.

${ }^{4}$ The reason why permit allocations in the Year 2010 are based on 1990 emission levels is because the Kyoto emissions targets are defined in terms of the allowed percentage changes from 1990 levels for all Annex B countries except for Bulgaria, Hungary, Poland, and Romania. Under the decision 9/CP.2, these four countries are allowed to use base years other than 1990: Bulgaria and Romania use 1989 as their base year; Hungary uses the average emissions between 1985 and 1987; and Poland uses 1988 (UNFCCC, 1996).

${ }^{5}$ Note that all of the equity criteria simulated here are allocation based, i.e., they relate to how the permits are initially distributed. This is in contrast to criteria that are outcome based, i.e., focused on the final relative impacts after trading. Allocation-based criteria are preferred because they are more straightforward, transparent, and specifiable with perfect certainty. Outcome-based criteria require predictions of the trading process and are subject to controversy over definition of the criteria themselves and the measure of welfare. They also require a more sophisticated model than that presented here (see Rose et al., 1998).

${ }^{6}$ Several analysts have confused reference bases and equity criteria, and actually expressed a preference for using the former in environmental policy. Reference bases do have the desirable properties of "focal points," a facilitating feature of negotiation processes. However, we ascribe primacy to equity principles. If global warming were an uncomplex issue that can be settled in a short time, we could endorse the more pragmatic "rule of thumb" approach. Because the issue is complex, and negotiations are likely to take years and to go through several stages, it is imperative they have a solid foundation. This is provided by equity criteria, which are well grounded in philosophy, law, political science, and economics. 
${ }^{7}$ In addition to the static reference bases utilized in this paper, dynamic reference bases might also be considered. Examples are the use of cumulative emissions (since carbon dioxide is a stock pollutant and hence its adverse effects stem from its build-up over time) or future economic activity (to take into account effects on future economic development) (see also Rose and Stevens, 1998).

${ }^{8}$ An upstream trading system would target fossil fuel producers and importers as regulated entities, thereby reducing the number of allowance holders to oil refineries and importers, natural gas pipelines, natural gas processing plants, coal mines and processing plants. Implemented effectively, an upstream system would capture virtually all fossil fuel use and carbon emissions in a national economy. Firms would raise fuel prices to offset the additional cost. In an upstream system the number of firms that has to be monitored for compliance is relatively small, and thus it is easier to administer. In contrast, a downstream trading system would be applied at the point of energy use, and, as such, a large number of diverse energy users are included. This would offer greater competition and stimulate more robust trading, thus likely leading to increased innovation. See Zhang (2000b) for a detailed discussion on upstream and downstream trading systems.

${ }^{9}$ States in each of the ten EPA regions are listed in Appendix A, and the basic data on which allowance allocations are based are presented in Appendix B.

${ }^{10}$ This is analogous to the issue of "hot air" associated with the situation in the former Soviet Union. Economic decline associated with a transition to a market-based economy in Russia and the Ukraine, as well as the associated more efficient energy pricing, have led to current emissions being even lower than 1990 levels. Thus, Russia and the Ukraine could conceivably sell permits for emissions that they would not even generate, thereby incurring a zero mitigation cost. Not surprisingly, this has raised a good deal of opposition (see Rose and Stevens, 2001). Modifications in the model presented here to factor in limits of hot air trading are presented in Zhang (2000a).

${ }^{11}$ It should be noted that the New England states have been leaders in regional efforts at greenhouse gas mitigation. The New England Governors Association recently signed an agreement to establish targets for GHG emission reductions and to consider trading of permits across states. In the meantime, these states have implemented several policies, such as conservation, that will promote GHG emission reductions. Of course, the mitigation issue is relatively less sensitive in this group of states because they are relatively smaller energy users than the national average and produce hardly any fossil fuels (see below).

${ }^{12}$ The shape of the cost function for mitigating carbon emissions has been studied extensively. For example, Nordhaus (1994) found that the logarithmic functional provided the best fit for the estimates of the marginal costs of mitigating a specific amount of carbon emissions among a number of economic modeling studies that he surveyed (a type of meta-analysis). Nordhaus (1994) used an analytical model to further derive a logarithmic relationship between the marginal costs and the percentage reduction.

${ }^{13}$ The Intergovernmental Panel on Climate Change estimates that it would require reduction of $60-80 \%$ in GHG emissions to stabilize atmospheric concentrations. Current international climate negotiations and policy analyses, however, focus on more modest goals. Also, given the existence of some very low cost abatement options in each country (e.g., conservation), as well as the very high cost and technological impossibility of abating all carbon emissions, $R_{i}$ will never take on the extreme values of 0 or 1 .

${ }^{14}$ The market equilibrium solution of our model is unique, so the same solution could be obtained without optimizing. The reason why we specify an objective function is that we use GAMS/MINOS, a solver mainly for optimization problems. The minimization of the total cost is a logical choice for an objective in the case of "costeffectiveness" analysis here (i.e., when a policy target is set and decision units seek to attain it at least cost). Had we used a software package that is specifically designed to solve a simultaneous equation system, then there would have been no need for an objective function. Note that the convexity conditions of both solutions are readily satisfied. Each of the individual regional marginal cost curves has properties conducive to overall convexity. Constraints are essentially linear. We have also undertaken sensitivity tests in other applications of the model that indicate an 
absence of convexity problems. Moreover, we obtained the identical solution for the cost-minimization and market equilibrium versions of the problem. This provides additional indirect evidence that convexity is not an issue.

${ }^{15}$ In international climate negotiations, the extent of usage of emissions trading has been subject to long and contentious debates. On the one hand, the U.S. and some other countries advocated unrestricted emissions trading. On the other hand, the European Union put forth a proposal for quantitative ceilings on the use of flexibility mechanisms (European Union, 1999), insisting that domestic abatement actions should be a main means of meeting emissions reductions required of each Annex 1 country. With the U.S. withdrawal from the Kyoto Protocol, the European Union dropped its previous insistence on a cap on the use of flexibility mechanisms. See Zhang (2000a, 2001) for a detailed discussion of these supplementarity provisions and on the assessment of the European Union proposal for ceilings on the use of Kyoto flexibility mechanisms.

${ }^{16}$ The shift is accomplished by altering the $\alpha_{i}$ parameter value (see, e.g., equation 1). The basic $\alpha_{i}$ value is 0.00357 for the U.S. as a whole. Given the functional form (negative $\alpha_{i}$ values), energy intensity and the parameter value have an inverse relationship. Thus, a region with an emission weighted fossil energy intensisty half as large as the U.S. average would have an $\alpha_{i}$ parameter value twice as large (-0.00714). These relative weighted fossil fuel intensity values are proportional to the ratios of $\mathrm{CO}_{2}$ emissions and GRP in Appendix B. For example, the South Central States have a $\mathrm{CO}_{2} / \mathrm{GRP}$ ratio of .000282, while the New England States have a ratio of .000083 . Thus, the $\alpha_{i}$ value for New England is 3.398 times that of the South Central States.

${ }^{17}$ Note that our analysis has other limitations on the cost side and omits the benefits side completely. First, our cost functions are based on a synthesis of the professional literature and include primarily GHG mitigation strategies such as conservation, interfuel substitution, and other fuel and input substitution. This omits, for example, the alternative of reducing carbon in the atmosphere by various means of carbon sequestration, such as tree planting. Rose and Oladosu (2002) have shown that incorporating sequestration can greatly reduce the total cost of reducing $\mathrm{CO}_{2}$. Unfortunately, data are inadequate to specify regional distinctions in sequestration costs at this time. Likely regional differences in these costs could significantly affect the results presented here, though not in the near term, such as the Kyoto compliance period (2008-12), since it takes some time (to allow for tree growth) for this option to take hold. (The term, "mitigation," is sometimes used to cover the broader set of tactics, including sequestration, while abatement is sometimes used to cover the more narrow set. We use the terms as synonyms with the clear understanding that we have not included carbon sequestration.) We have omitted the benefits of GHG mitigation as well, which are also likely to have significant differential impacts across regions (see, e.g., Solomon and Lee, 2000). Benefit estimates are especially tenuous, and we have sought to illustrate major issues and the usefulness of our methodology with as strong a data underpinning as possible. The reader is referred to Rose and Stevens (2001) and Stevens and Rose (2002) for insight into the difference that the inclusion of benefits makes in permit trading systems in the international domain. Of course, actual policy design must include some assessment of benefits.

${ }^{18}$ We point out that our results are presented in terms of 1990 U.S. dollars (1990 is the Kyoto reference period). Thus, our $\$ 20$ permit price cap corresponds to approximately $\$ 25$ in today's terms. Note also that there are disagreements over the appropriate price cap. For example, Kopp et al. (1999) have suggested a ceiling price of $\$ 25 / \mathrm{tC}$ in 2002 , rising by $7 \%$ each year (above inflation) through 2007. A major justification for a ceiling is that it facilitates a "ramping-up" to the attainment of Kyoto targets.

${ }^{19}$ We have abstracted from some important features in order to reduce the complexity of the analysis and for lack of data. First, although permit allocations are assigned on a regional basis, it will be individual businesses (and possibly households) that actually do the trading. Still, they are as likely to pursue optimizing behavior as much and even more so than state or regional government entities. Note also that we are measuring welfare in income terms and have not invoked the use of individual or regional utility functions, which could alter some of our results.

${ }^{20}$ Note also that the Sovereignty (emissions-based) formula most closely resembles the "polluter-pay" principle.

${ }^{21}$ Note that the one-third reduction in $\mathrm{CO}_{2}$ emissions corresponding to a one-third reduction in mitigation costs suggests the cost function is approximately linear at this point. Note, however, that it soon becomes non-linear. 
Simulations performed for the case of a 7\% reduction below 1990 levels (the full U.S. commitment without any international permit purchases) represents only a $40 \%$ increase over the $5 \%$ mitigation level of Table IIIA, but incurs a $200 \%$ increase in costs.

${ }^{22}$ The skewed permit allocation for the Egalitarian criterion is not nearly as great as that in the application of the criterion in the international domain, e.g., consider the U.S. vs. India (see Rose and Stevens, 1998; Rose et al., 1998).

${ }^{23}$ Note that while the total cost impact on permit holders does not vary across the permit distributions presented here, it would differ for the case where permits are auctioned. This is because, under grandfathering approaches, a high level of emissions is free, while, under the auction approach, all emissions must be purchased. Of course, the difference is not a real cost, but simply a transfer. In the short run, the two approaches are equivalent since decisions are made at the margin, and the permit price is essentially the same for grandfathering or auctioning. However, long-run implications may differ. In addition, auctioning of permits is sometimes considered to be an equity criterion itself; however, it begs the question of how to redistribute the federal government's revenues from permit sales. Essentially, some other criterion must be appended to resolve this issue.

${ }^{24}$ The results for the capped $\$ 20 / \mathrm{tC}$ permit price in this and the following cases are not shown because they bear a similar proportional relationship to the $\$ 25.25 / \mathrm{tC}$ case as above (i.e., costs and trades are about two thirds of the flexible price totals because only two-thirds as many emissions are reduced).

${ }^{25}$ Note that we have assumed modest growth rates in per capita regional product and in carbon emissions, which in light of the recent economic recession and factors associated with fossil energy use would appear reasonable. The GRP growth rates are applied to all regions equally in the absence of reliable projections to the contrary. Differential regional economic growth, however, would only affect our results significantly if it were especially large. The South West Region is expected to be a growth leader but not enough as to render the results for it in our analysis especially unusual. The carbon emissions projections were regionally differentiated, but the results could differ significantly even if the relative growth rates stayed the same and the overall rate was far below actual levels, because of our assumption that no region would be granted "excess" permits. 


\section{REFERENCES}

Brooke, A., Kendrick, D., and Meeraus, A. 1996. GAMS: A User's Guide, Redwood City, CA: Scientific Press.

(CCAP) Center for Clean Air Policy. 2002. State and Local Climate Change Policy Actions, Washington, DC.

Coase, R. 1960. “The Problem of Social Cost," Journal of Law and Economics 3: 1-44.

Easterling, W. 1997. "Why Regional Studies are Needed in the Development of Full-Scale Integrated Assessment Modelling of Global Change Processes," Global Environmental Change 7: 337-56.

Easterling, W., Polsky, C., Goodin, D., Mayfield, M., Muraco, W., and Yarnal, B. 1998.

"Changing Places, Changing Emissions: The Cross-Scale Reliability of Greenhouse Gas Emission Inventories in the U.S.," Local Environment 3: 247-62.

Ellerman, A., Joskow, P., Schmalensee, R., Montero, J., and Bailey, E. 2000. Market for Clean Air: The U.S. Acid Rain Program, New York: Cambridge University Press.

European Union. 1999. "Community Strategy on Climate Change: Council Conclusions," No. 8346/99, 18 May, Brussels, Belgium.

Kopp, R., Morgenstern, R., Pizer, W., and Toman, M. 1999. "A Proposal for Credible Early Action in the U.S. Climate Change Policy," Washington, DC: Resources for the Future.

Rose, A. 1992. "Equity Considerations of Tradeable Carbon Entitlements," in S. Barrett, M. Grubb, K. Roland, A. Rose, R. Sandor, and T. Tietenberg, Combating Global Warming: Study on a Global System of Tradeable Carbon Emission Entitlements. New York: United Nations (UNCTAD).

Rose, A. and Oladosu, G. 2002. "Greenhouse Gas Reduction in the U.S.: Identifying Winners and Losers in an Expanded Permit Trading System," Energy Journal 23(1): 1-18.

Rose, A. and Stevens, B. 1993. "The Efficiency and Equity of Marketable Permits for $\mathrm{CO}_{2}$ Emissions," Resource and Energy Economics 15(1): 117-46.

Rose, A., and Stevens, B. K. 1998. "Will a Global Warming Agreement be Fair to Developing Countries?" International Journal of Environment and Pollution 9: 157-77.

Rose, A. and Stevens, B. K. 2001. "An Economic Analysis of Flexible Permit Trading in the Kyoto Protocol," International Environmental Agreements: Politics, Law and Economics 1(2): 219-42. 
Rose, A., and Webber, D. 1992. "Interregional Equity and Acid Rain Policy,” Department of Energy, Environmental, and Mineral Economics, The Pennsylvania State University, University Park, PA.

Rose, A., Stevens, B. K., Edmonds, J., and Wise, M. 1998. "International Equity and Differentiation in Global Warming Policy," Environmental and Resource Economics 12(1): $25-51$.

Solomon, B., and Lee, R. 2000. "Emissions Trading Systems and Environmental Justice," Environment 42(8): 32-45.

Stevens, B., and Rose, A. 2002. "A Dynamic Analysis of the Marketable Permits Approach to Global Warming Policy: A Comparison of Spatial and Temporal Flexibility," Journal of Environmental Economics and Management 44(1): 45-69.

Tietenberg, T. 1985. Emissions Trading: An Exercise in Reforming Pollution Policy, Washington, DC: Resources for the Future.

(UNFCCC) United Nations Framework Convention on Climate Change. 1996. "Report of the Conference of the Parties on its Second Session, held at Geneva from 8 to 19 July 1996: Action Taken by the Conference of the Parties on its Second Session," FCCC/CP/1996/15/Add. 1, Bonn, Germany.

U.S. Bureau of Economic Analysis. 2002a. "Annual State Personal Income," http://www.bea.doc.gov/bea/regional/spi/.

U.S. Bureau of Economic Analysis. 2002b. "Gross State Product Data," http://www.bea.doc.gov/bea/regional/gsp/action.cfm.

U.S. Environmental Protection Agency. 2002. "State Summary Reports," http://yosemite.epa.gov/globalwarming/ghg.nsf/emissions/State Summary Reports.

Zhang, Z. X. 2000a. "Estimating the Size of the Potential Market for the Kyoto Flexibility Mechanisms," Weltwirtschaftliches Archiv - Review of World Economics 136 (3): 491521.

Zhang, Z. X. 2000b. "The Design and Implementation of an International Greenhouse Gas Emissions Trading Scheme," Environment and Planning C: Government and Policy 18(3): 321-37.

Zhang, Z. X. 2001. "An Assessment of the EU Proposal for Ceilings on the Use of Kyoto Flexibility Mechanisms," Ecological Economics 37(1): 53-69. 
APPENDIX A

\section{U.S. EPA REGIONS}

Region 1 (New England) Connecticut, Maine, Massachusetts, New Hampshire, Rhode Island, and Vermont

Region 2 (NY/NJ) New Jersey, and New York

Region 3 (Mid-Atlantic) Delaware, Maryland, Pennsylvania, Virginia, West Virginia, and the District of Columbia

Region 4 (South East) Alabama, Florida, Georgia, Kentucky, Mississippi, North Carolina, South Carolina, and Tennessee

Region 5 (North Central) Illinois, Indiana, Michigan, Minnesota, Ohio, and Wisconsin

Region 6 (South Central) Arkansas, Louisiana, New Mexico, Oklahoma, and Texas

Region 7 (Plains) Iowa, Kansas, Missouri, and Nebraska

Region 8 (Mountain) Colorado, Montana, North Dakota, South Dakota, Utah and Wyoming

Region 9 (South West) Arizona, California, Hawaii, and Nevada

Region 10 (North West) Alaska, Idaho, Oregon, and Washington 
APPENDIX B. BASIC DATA FOR YEAR 2010

\begin{tabular}{|l|c|c|c|}
\hline \multicolumn{1}{|c|}{ Region } & \multicolumn{1}{|c|}{$\begin{array}{c}\text { Population }^{\mathrm{a}} \\
\text { (thousands) }\end{array}$} & $\begin{array}{c}\mathrm{GRP}^{\mathrm{b}} \\
\text { (millions) }\end{array}$ & $\begin{array}{c}\mathrm{CO}_{2} \text { Emissions }^{\mathrm{c}} \\
\text { (million tons of } \\
\text { carbon) }\end{array}$ \\
\hline New England & 14,190 & 515,102 & 43 \\
\hline $\begin{array}{l}\text { New York/New } \\
\text { Jersey }\end{array}$ & 27,234 & $1,051,364$ & 131 \\
\hline Mid Atlantic & 28,869 & 929,127 & 249 \\
\hline South East & 56,964 & $1,491,362$ & 262 \\
\hline North Central & 50,917 & $1,624,909$ & 77 \\
\hline South Central & 36,151 & 998,411 & 67 \\
\hline Plains & 13,481 & 397,825 & 119 \\
\hline Mountain & 10,340 & 281.169 & 44 \\
\hline South West & 46,827 & $1,375,822$ & 1,355 \\
\hline North West & 12,737 & 352,905 & \\
\hline Total & 297,710 & $9,017,996$ & 282 \\
\hline
\end{tabular}

${ }^{a}$ U.S. BEA (2002a). Year 1999 data projected forward with 1.0 percent average annual growth rate for each region. ${ }^{b}$ U.S. BEA (2002b). Year 2000 data projected forward with 1.2 percent average annual growth rate for each region. 'U.S. EPA (2002). Year 1997 data projected forward with 0.5 percent average annual growth rate for U.S. as a whole but regional differentials based on projections of fossil energy use. 
TABLE I. ALTERNATIVE EQUITY CRITERIA FOR GREENHOUSE GAS MITIGATION POLICY

\begin{tabular}{|c|c|c|c|}
\hline Criterion & Basic Definition & General Operational Rule & Operational Rule for $\mathrm{CO}_{2}$ Permits \\
\hline \multicolumn{4}{|l|}{ Allocation-Based } \\
\hline Sovereignty & $\begin{array}{l}\text { All regions have an equal right to pollute } \\
\text { and to be protected from pollution }\end{array}$ & $\begin{array}{l}\text { Cut back emissions in a proportional manner } \\
\text { across all regions }\end{array}$ & $\begin{array}{l}\text { Distribute permits in proportion to emissions, } \\
\text { energy-use, land area, etc. }\end{array}$ \\
\hline Egalitarian & $\begin{array}{l}\text { All people have an equal right to pollute or } \\
\text { to be protected from pollution }\end{array}$ & Allow emissions in proportion to population & Distribute permits in proportion to population \\
\hline Ability to Pay & $\begin{array}{l}\text { Mitigation costs should vary directly with } \\
\text { regional economic well-being }\end{array}$ & $\begin{array}{l}\text { Richer regions should shoulder a higher } \\
\text { proportion of gross cost of abatement }{ }^{\mathrm{a}}\end{array}$ & Distribute permits inversely to GRP \\
\hline Econ Activity & $\begin{array}{l}\text { All regions should be allowed to maintain } \\
\text { their standard of living }\end{array}$ & Richer regions should not be penalized & Distribute permits in proportion to GRP \\
\hline \multicolumn{4}{|l|}{ Outcome-Based } \\
\hline Horizontal & $\begin{array}{l}\text { All regions should be treated equally } \\
\text { In terms of changes in welfare }\end{array}$ & $\begin{array}{l}\text { Equalize net welfare change across } \\
\text { regions (net loss as proportion of GRP equal } \\
\text { for each region) } b\end{array}$ & $\begin{array}{l}\text { Distribute permits to equalize net welfare } \\
\text { change (net loss as proportion of GRP equal } \\
\text { for each region) }{ }^{b}\end{array}$ \\
\hline Vertical & $\begin{array}{l}\text { Welfare gains should vary inversely with } \\
\text { regional economic well-being; welfare } \\
\text { losses should vary directly with GRP }\end{array}$ & $\begin{array}{l}\text { Progressively share net welfare change across } \\
\text { regions (net loss proportions directly } \\
\text { correlated with per capita GRP)b }\end{array}$ & $\begin{array}{l}\text { Progressively distribute permits (net loss } \\
\text { proportions directly correlated with per capita } \\
\text { GRP) }\end{array}$ \\
\hline Compensation & No region should be made worse off & Compensate net losing regions & $\begin{array}{l}\text { Distribute permits so no region suffers a net } \\
\text { loss of welfare }\end{array}$ \\
\hline \multicolumn{4}{|l|}{ Process-Based } \\
\hline Rawls' Maximin & $\begin{array}{l}\text { The welfare of the worst-off region should } \\
\text { be maximized }\end{array}$ & Maximize the net benefit to the poorest regions & $\begin{array}{l}\text { Distribute largest proportion of net welfare } \\
\text { gain to poorest regions }\end{array}$ \\
\hline Consensus & The negotiation process is fair & Seek a political solution promoting stability & $\begin{array}{l}\text { Distribute permits in a manner that satisfies } \\
\text { the (power weighted) majority of regions }\end{array}$ \\
\hline
\end{tabular}

${ }^{a}$ Gross cost refers to mitigation cost only and does not include benefits or permit transactions.

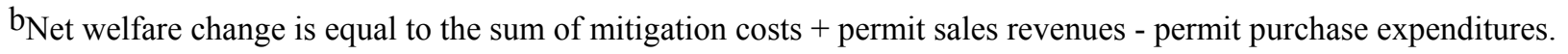


TABLE II. INITIAL PERMIT ALLOCATIONS ${ }^{\mathrm{a}}$

(million tons of carbon)

\begin{tabular}{|c|c|c|c|c|c|c|c|c|}
\hline \multirow[b]{2}{*}{ Region } & \multirow[b]{2}{*}{$\begin{array}{l}1990 \text { Actual } \\
\mathrm{CO}_{2} \text { Emissions }\end{array}$} & \multirow[b]{2}{*}{$\begin{array}{l}2010 \text { Projected } \\
\mathrm{CO}_{2} \text { Emissions }\end{array}$} & \multicolumn{6}{|c|}{ Permit Allocation Criteria ${ }^{b}$} \\
\hline & & & (emissions) & Egalitarian & $\begin{array}{l}\text { Economic } \\
\text { Activity }\end{array}$ & $\begin{array}{c}\text { Ability To } \\
\text { Pay }\end{array}$ & $\begin{array}{l}\text { Sovereignty } \\
\text { (energy use) }\end{array}$ & $\begin{array}{r}\text { Sovereignty } \\
\text { (energy prod) }\end{array}$ \\
\hline NEngland & 49 & 43 & (47) 43 & (59) 43 & (71) 43 & (85) 43 & (39) 39 & (0) 0 \\
\hline $\mathrm{NY} / \mathrm{NJ}$ & 86 & 82 & $(82)$ & (113) 82 & (144) 82 & $(75)$ & (77) & (1) \\
\hline MidAt & 132 & 131 & $(125) \quad 126$ & (120) 131 & (128) 131 & $(108) \quad 131$ & (119) 119 & $(150)$ \\
\hline NCentral & 247 & 262 & (234) 235 & (212) 262 & (223) 262 & (109) 198 & $(241)$ & $(67)$ \\
\hline SCentral & 265 & 282 & (251) 252 & (150) 186 & (137) 183 & (146) 228 & (271) 271 & $(431)$ \\
\hline Plains & 70 & 77 & (67) 67 & (56) 69 & $(55)$ & (128) 77 & $(67)$ & (26) \\
\hline Mountain & 65 & 67 & $(62)$ & (43) 53 & (39) & $(151)$ & $(58)$ & (299) \\
\hline
\end{tabular}

${ }^{\text {a }}$ Total initial permit allocation equals $95 \%$ of 1990 emission level after international permit trading (U.S. purchases permits to make up for remaining $2 \%$ of its Kyoto commitment).

${ }^{\mathrm{b}}$ Numbers in parentheses are unadjusted allocations (see text).

${ }^{\mathrm{c}}$ The reason why the total amount of permits allocated in the Sovereignty Energy Production case is less than the corresponding values in the other five cases examined is that New England, which produces almost no fossil fuels, is dropped from consideration by definition. 
TABLE IIIA. COST IMPACTS OF SOVEREIGNTY EQUITY PERMIT ASSIGNMENTS, YEAR 2010: 5\% REDUCTION OF 1990 BASELINE EMISSIONS

(billion 1990 dollars)

\begin{tabular}{|c|c|c|c|c|c|c|}
\hline \multirow[b]{2}{*}{ Region } & \multicolumn{3}{|c|}{ Before Trading } & \multicolumn{3}{|c|}{ After Trading } \\
\hline & Mitigation Cost & Trading Cost & Net Cost & Mitigation Cost & Trading Cost & Net Cost \\
\hline NEng & 0.00 & 0.00 & 0.00 & 0.09 & -0.18 & -0.09 \\
\hline $\mathrm{NY} / \mathrm{NJ}$ & 0.00 & 0.00 & 0.00 & 0.17 & -0.35 & -0.18 \\
\hline MidAt & 0.03 & 0.00 & 0.03 & 0.14 & -0.16 & -0.02 \\
\hline SEast & 0.70 & 0.00 & 0.70 & 0.24 & 0.34 & 0.58 \\
\hline NCent & 0.46 & 0.00 & 0.46 & 0.25 & 0.18 & 0.43 \\
\hline SCent & 0.88 & 0.00 & 0.88 & 0.16 & 0.43 & 0.59 \\
\hline Plains & 0.25 & 0.00 & 0.25 & 0.06 & 0.12 & 0.19 \\
\hline Mount & 0.09 & 0.00 & 0.09 & 0.04 & 0.04 & 0.08 \\
\hline SWest & 0.01 & 0.00 & 0.01 & 0.23 & -0.41 & -0.17 \\
\hline NWest & 0.06 & 0.00 & 0.06 & 0.06 & 0.00 & 0.06 \\
\hline Total & 2.47 & 0.00 & 2.47 & 1.46 & 0.00 & 1.46 \\
\hline
\end{tabular}

Note: Permit price $=\$ 25.25 / \mathrm{tC}$. 
TABLE IIIB. COST IMPACTS OF SOVEREIGNTY EQUITY PERMIT ASSIGNMENTS, YEAR 2010: \$20t C PERMIT PRICE (3.3\% REDUCTION OF 1990 BASELINE EMISSIONS)

(billion 1990 dollars)

\begin{tabular}{|c|c|c|c|c|c|c|}
\hline \multirow[b]{2}{*}{ Region } & \multicolumn{3}{|c|}{ Before Trading } & \multicolumn{3}{|c|}{ After Trading } \\
\hline & Mitigation Cost & Trading Cost & Net Cost & Mitigation Cost & Trading Cost & Net Cost \\
\hline NEng & 0.00 & 0.00 & 0.00 & 0.06 & -0.12 & -0.06 \\
\hline NY/NJ & 0.00 & 0.00 & 0.00 & 0.11 & -0.23 & -0.12 \\
\hline MidAt & 0.00 & 0.00 & 0.01 & 0.09 & -0.13 & -0.03 \\
\hline SEast & 0.54 & 0.00 & 0.54 & 0.16 & 0.27 & 0.43 \\
\hline NCent & 0.33 & 0.00 & 0.33 & 0.16 & 0.14 & 0.30 \\
\hline SCent & 0.60 & 0.00 & 0.60 & 0.11 & 0.29 & 0.40 \\
\hline Plains & 0.16 & 0.00 & 0.16 & 0.04 & 0.08 & 0.12 \\
\hline Mount & 0.03 & 0.00 & 0.03 & 0.03 & 0.00 & 0.03 \\
\hline SWest & 0.00 & 0.00 & 0.00 & 0.16 & -0.30 & -0.14 \\
\hline NWest & 0.04 & 0.00 & 0.04 & 0.04 & 0.00 & 0.04 \\
\hline Total & 2.47 & 0.00 & 1.72 & 0.96 & 0.00 & 0.96 \\
\hline
\end{tabular}


TABLE IVA. COST IMPACTS OF EGALITARIAN EQUITY PERMIT ASSIGNMENTS, YEAR 2010: 5\% REDUCTION OF 1990 BASELINE EMISSIONS

(billion 1990 dollars)

\begin{tabular}{|c|c|c|c|c|c|c|}
\hline \multirow[b]{2}{*}{ Region } & \multicolumn{3}{|c|}{ Before Trading } & \multicolumn{3}{|c|}{ After Trading } \\
\hline & Mitigation Cost & Trading Cost & Net Cost & Mitigation Cost & Trading Cost & Net Cost \\
\hline NEng & 0.00 & 0.00 & 0.00 & 0.09 & -0.18 & -0.09 \\
\hline $\mathrm{NY} / \mathrm{NJ}$ & 0.00 & 0.00 & 0.00 & 0.17 & -0.35 & -0.18 \\
\hline MidAt & 0.01 & 0.00 & 0.00 & 0.14 & -0.29 & -0.15 \\
\hline SEast & 0.00 & 0.00 & 0.00 & 0.24 & 0.50 & 0.25 \\
\hline NCent & 0.00 & 0.00 & 0.00 & 0.25 & 0.50 & 0.26 \\
\hline SCent & 9.84 & 0.00 & 9.84 & 0.16 & 2.09 & 2.26 \\
\hline Plains & 0.16 & 0.00 & 0.16 & 0.06 & 0.07 & 0.14 \\
\hline Mount & 0.74 & 0.00 & 0.74 & 0.04 & 0.26 & 0.31 \\
\hline SWest & 0.00 & 0.00 & 0.00 & 0.23 & -0.48 & -0.25 \\
\hline NWest & 0.00 & 0.00 & 0.00 & 0.06 & 0.12 & 0.06 \\
\hline Total & 10.73 & 0.00 & 10.73 & 1.46 & 0.00 & 1.46 \\
\hline
\end{tabular}

Note: Permit price $=\$ 25.25 / \mathrm{tC}$. 
TABLE IVB. COST IMPACTS OF EGALITARIAN EQUITY PERMIT ASSIGNMENTS, YEAR 2010: \$20/T C PERMIT PRICE (3.3\% REDUCTION OF 1990 BASELINE EMISSIONS)

(billion 1990 dollars)

\begin{tabular}{|l|c|c|c|c|c|c|}
\hline \multirow{2}{*}{ Region } & \multicolumn{3}{|c|}{ Before Trading } & \multicolumn{3}{c|}{ After Trading } \\
\cline { 2 - 7 } NEng & Mitigation Cost & Trading Cost & Net Cost & Mitigation Cost & Trading Cost & Net Cost \\
\hline NY/NJ & 0.00 & 0.00 & 0.00 & 0.06 & -0.12 & -0.06 \\
\hline MidAt & 0.00 & 0.00 & 0.00 & 0.11 & -0.23 & -0.19 \\
\hline SEast & 0.00 & 0.00 & 0.00 & 0.09 & 0.32 & -0.09 \\
\hline NCent & 0.00 & 0.00 & 0.00 & 0.16 & 0.33 & -0.16 \\
\hline SCent & 0.00 & 0.00 & 0.00 & 0.16 & 0.11 & -0.17 \\
\hline Plains & 7.21 & 0.00 & 7.21 & 0.04 & 0.02 & 0.15 \\
\hline Mount & 0.02 & 0.00 & 0.02 & 0.03 & -0.32 & 0.17 \\
\hline SWest & 0.37 & 0.00 & 0.37 & 0.16 & -0.16 \\
\hline NWest & 0.00 & 0.00 & 0.00 & 0.04 & -0.08 & -0.04 \\
\hline Total & 0.00 & 0.00 & 0.00 & 0.96 & 0.00 & 0.96 \\
\hline
\end{tabular}


TABLE V. COST IMPACTS OF ECONOMIC ACTIVITY EQUITY PERMIT ASSIGNMENTS, YEAR 2010: 5\% REDUCTION OF 1990 BASELINE EMISSIONS

(billion 1990 dollars)

\begin{tabular}{|c|c|c|c|c|c|c|}
\hline \multirow[b]{2}{*}{ Region } & \multicolumn{3}{|c|}{ Before Trading } & \multicolumn{3}{|c|}{ After Trading } \\
\hline & Mitigation Cost & Trading Cost & Net Cost & Mitigation Cost & Trading Cost & Net Cost \\
\hline NEng & 0.00 & 0.00 & 0.00 & 0.09 & -0.18 & -0.09 \\
\hline $\mathrm{NY} / \mathrm{NJ}$ & 0.00 & 0.00 & 0.00 & 0.17 & -0.35 & -0.18 \\
\hline MidAt & 0.00 & 0.00 & 0.00 & 0.14 & -0.29 & -0.15 \\
\hline SEast & 0.00 & 0.00 & 0.00 & 0.24 & -0.50 & -0.25 \\
\hline NCent & 0.00 & 0.00 & 0.00 & 0.25 & -0.50 & -0.26 \\
\hline SCent & 10.51 & 0.00 & 10.51 & 0.16 & 2.17 & 2.33 \\
\hline Plains & 0.04 & 0.00 & 0.04 & 0.06 & -0.03 & 0.04 \\
\hline Mount & 0.85 & 0.00 & 0.85 & 0.04 & 0.29 & 0.33 \\
\hline SWest & 0.00 & 0.00 & 0.00 & 0.23 & -0.48 & -0.25 \\
\hline NWest & 0.00 & 0.00 & 0.00 & 0.06 & -0.12 & -0.06 \\
\hline Total & 11.40 & 0.00 & 11.40 & 1.46 & 0.00 & 1.46 \\
\hline
\end{tabular}

Note: Permit price $=\$ 25.25 / \mathrm{tC}$. 
TABLE VI. COST IMPACTS OF ABILITY TO PAY EQUITY PERMIT ASSIGNMENTS, YEAR 2010: 5\% REDUCTION OF 1990 BASELINE EMISSIONS

(billion 1990 dollars)

\begin{tabular}{|l|c|c|c|c|c|c|}
\hline \multirow{2}{*}{\multicolumn{1}{|c|}{ Region }} & \multicolumn{3}{|c|}{ Before Trading } & \multicolumn{3}{c|}{ After Trading } \\
\cline { 2 - 7 } & Mitigation Cost & Trading Cost & Net Cost & Mitigation Cost & Trading Cost & Net Cost \\
\hline NEng & 0.00 & 0.00 & 0.00 & 0.09 & -0.18 & -0.09 \\
\hline NY/NJ & 0.00 & 0.00 & 0.00 & 0.17 & -0.35 & -0.18 \\
\hline MidAt & 0.00 & 0.00 & 0.00 & 0.14 & -0.29 & -0.50 \\
\hline SEast & 0.00 & 0.00 & 0.00 & 0.24 & 1.11 & 1.03 \\
\hline NCent & 2.72 & 0.00 & 2.72 & 0.25 & -0.25 \\
\hline SCent & 2.93 & 0.00 & 2.93 & 0.16 & 0.13 & -0.06 \\
\hline Mount & 0.00 & 0.00 & 0.00 & 0.04 & -0.09 & -0.04 \\
\hline SWest & 0.00 & 0.00 & 0.00 & 0.23 & -0.48 & -0.25 \\
\hline NWest & 0.00 & 0.00 & 0.00 & 0.06 & -0.12 & -0.06 \\
\hline Total & 0.00 & 0.00 & 0.00 & 1.46 & 0.00 & 1.46 \\
\hline
\end{tabular}

Note: Permit price $=\$ 25.25 / \mathrm{tC}$. 
TABLE VII. COST IMPACTS OF SOVEREIGNTY (ENERGY USE) EQUITY PERMIT ASSIGNMENTS, YEAR 2010: 5\% REDUCTION OF 1990 BASELINE EMISSIONS

(billion 1990 dollars)

\begin{tabular}{|c|c|c|c|c|c|c|}
\hline \multirow[b]{2}{*}{ Region } & \multicolumn{3}{|c|}{ Before Trading } & \multicolumn{3}{|c|}{ After Trading } \\
\hline & Mitigation Cost & Trading Cost & Net Cost & Mitigation Cost & Trading Cost & Net Cost \\
\hline NEng & 0.03 & 0.00 & 0.03 & 0.09 & -0.08 & 0.01 \\
\hline $\mathrm{NY} / \mathrm{NJ}$ & 0.02 & 0.00 & 0.02 & 0.17 & -0.23 & -0.06 \\
\hline MidAt & 0.16 & 0.00 & 0.16 & 0.14 & 0.02 & 0.16 \\
\hline SEast & 0.70 & 0.00 & 0.70 & 0.24 & 0.34 & 0.58 \\
\hline NCent & 0.28 & 0.00 & 0.28 & 0.25 & 0.03 & 0.27 \\
\hline SCent & 0.12 & 0.00 & 0.12 & 0.16 & -0.05 & 0.11 \\
\hline Plains & 0.25 & 0.00 & 0.25 & 0.06 & 0.12 & 0.19 \\
\hline Mount & 0.30 & 0.00 & 0.30 & 0.04 & 0.14 & 0.18 \\
\hline SWest & 0.08 & 0.00 & 0.08 & 0.23 & -0.21 & 0.03 \\
\hline NWest & 0.01 & 0.00 & 0.01 & 0.06 & -0.07 & -0.01 \\
\hline Total & 1.93 & 0.00 & 1.93 & 1.46 & 0.00 & 1.46 \\
\hline
\end{tabular}

Note: Permit price $=\$ 25.25 / \mathrm{tC}$. 
TABLE VIII. COST IMPACTS OF SOVEREIGNTY (ENERGY PRODUCTION) PERMIT ASSIGNMENTS, YEAR 2010: 5\% REDUCTION OF 1990 BASELINE EMISSIONS)

(billion 1990 dollars)

\begin{tabular}{|c|c|c|c|c|c|c|}
\hline \multirow[b]{2}{*}{ Region } & \multicolumn{3}{|c|}{ Before Trading } & \multicolumn{3}{|c|}{ After Trading } \\
\hline & Mitigation Cost & Trading Cost & Net Cost & Mitigation Cost & Trading Cost & Net Cost \\
\hline $\mathrm{NY} / \mathrm{NJ}$ & 9.37 & 0.00 & 9.37 & 0.19 & 1.73 & 1.93 \\
\hline MidAt & 0.00 & 0.00 & 0.00 & 0.16 & -0.33 & -0.17 \\
\hline SEast & 0.00 & 0.00 & 0.00 & 0.28 & -0.57 & -0.29 \\
\hline NCent & 0.97 & 0.00 & 0.97 & 0.28 & 0.48 & 0.76 \\
\hline SCent & 0.00 & 0.00 & 0.00 & 0.19 & -0.38 & -0.19 \\
\hline Plains & 0.00 & 0.00 & 0.00 & 0.07 & -0.15 & -0.08 \\
\hline Mount & 0.00 & 0.00 & 0.00 & 0.05 & -0.10 & -0.05 \\
\hline SWest & 0.00 & 0.00 & 0.00 & 0.27 & -0.55 & -0.28 \\
\hline NWest & 0.00 & 0.00 & 0.00 & 0.07 & -0.14 & -0.07 \\
\hline Total & 10.35 & 0.00 & 10.35 & 1.56 & 0.00 & 1.56 \\
\hline
\end{tabular}

Note: Permit price $=\$ 27.01 / \mathrm{tC}$. 
TABLE IX. SUMMARY OF NET COST IN PERMIT TRADING SIMULATIONS, YEAR 2010 (billion 1990 dollars)

\begin{tabular}{|c|c|c|c|c|c|c|}
\hline Region & $\begin{array}{l}\text { Sovereignty } \\
\text { (emissions) }\end{array}$ & Egalitarian & $\begin{array}{l}\text { Economic } \\
\text { Activity }\end{array}$ & Ability To Pay & $\begin{array}{l}\text { Sovereignty } \\
\text { (energy use) }\end{array}$ & $\begin{array}{l}\text { Sovereignty } \\
\text { (energy prod) }\end{array}$ \\
\hline NEng & -0.09 & -0.09 & -0.09 & -0.09 & 0.01 & - \\
\hline NY/NJ & -0.18 & -0.18 & -0.18 & -0.18 & -0.06 & 1.93 \\
\hline MidAt & -0.02 & -0.15 & -0.15 & -0.15 & 0.16 & -0.17 \\
\hline SEast & 0.58 & -0.25 & -0.25 & -0.25 & 0.58 & -0.29 \\
\hline NCent & 0.43 & -0.26 & -0.26 & 1.36 & 0.27 & 0.76 \\
\hline SCent & 0.59 & 2.26 & 2.33 & 1.20 & 0.11 & -0.19 \\
\hline Plains & 0.19 & 0.14 & 0.04 & -0.07 & 0.19 & -0.08 \\
\hline Mount & 0.08 & 0.31 & 0.33 & -0.04 & 0.18 & -0.05 \\
\hline SWest & -0.17 & -0.25 & -0.25 & -0.25 & 0.03 & -0.28 \\
\hline NWest & 0.06 & -0.06 & -0.06 & -0.06 & -0.01 & -0.07 \\
\hline Total & 1.46 & 1.46 & 1.46 & 1.46 & .146 & 1.56 \\
\hline
\end{tabular}




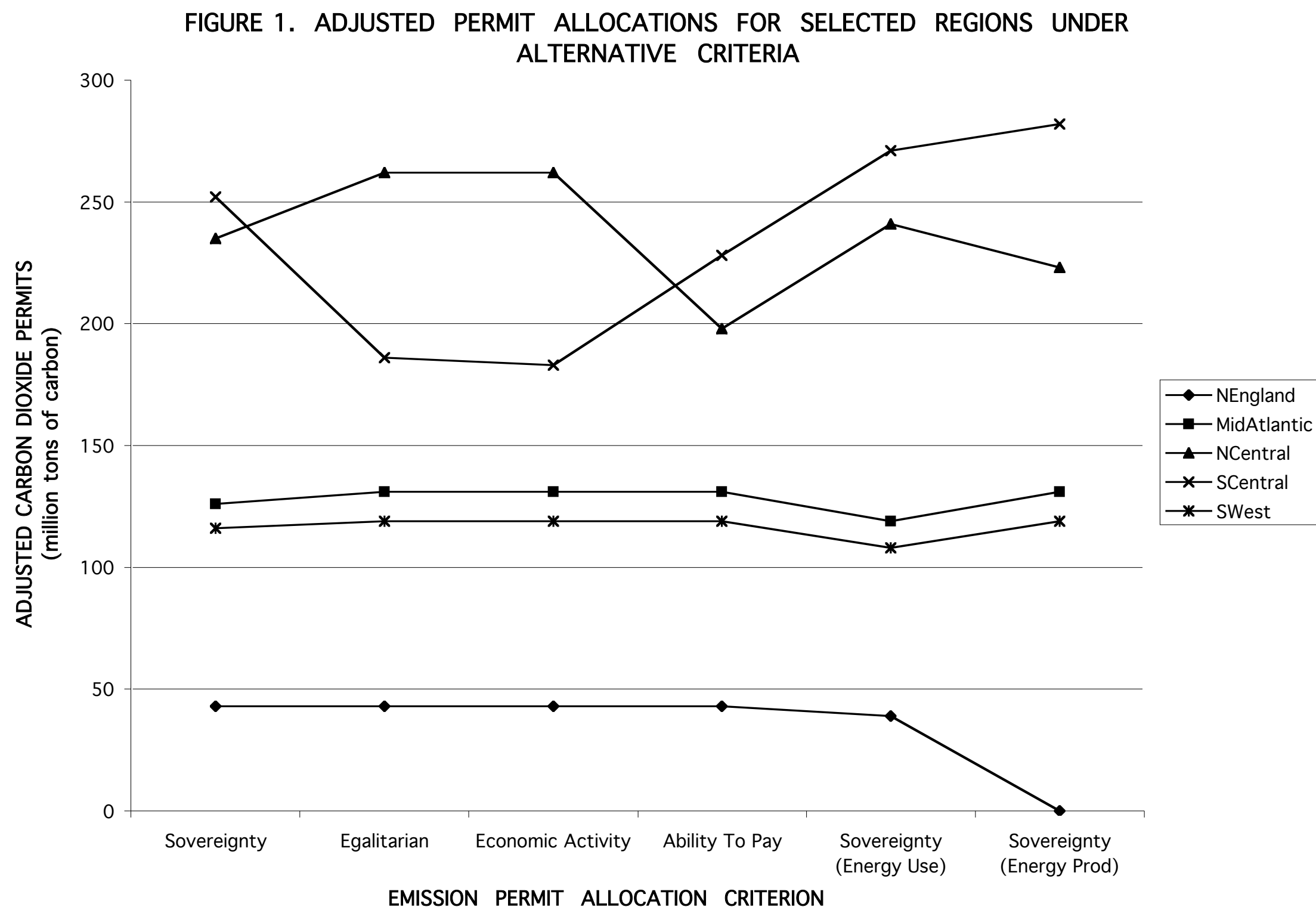


FIGURE 2. NET COST OF MEETING U.S. KYOTO PROTOCOL COMMITMENTS IN SELECTED REGIONS UNDER ALTERNATIVE PERMIT ALLOCATION CRITERIA

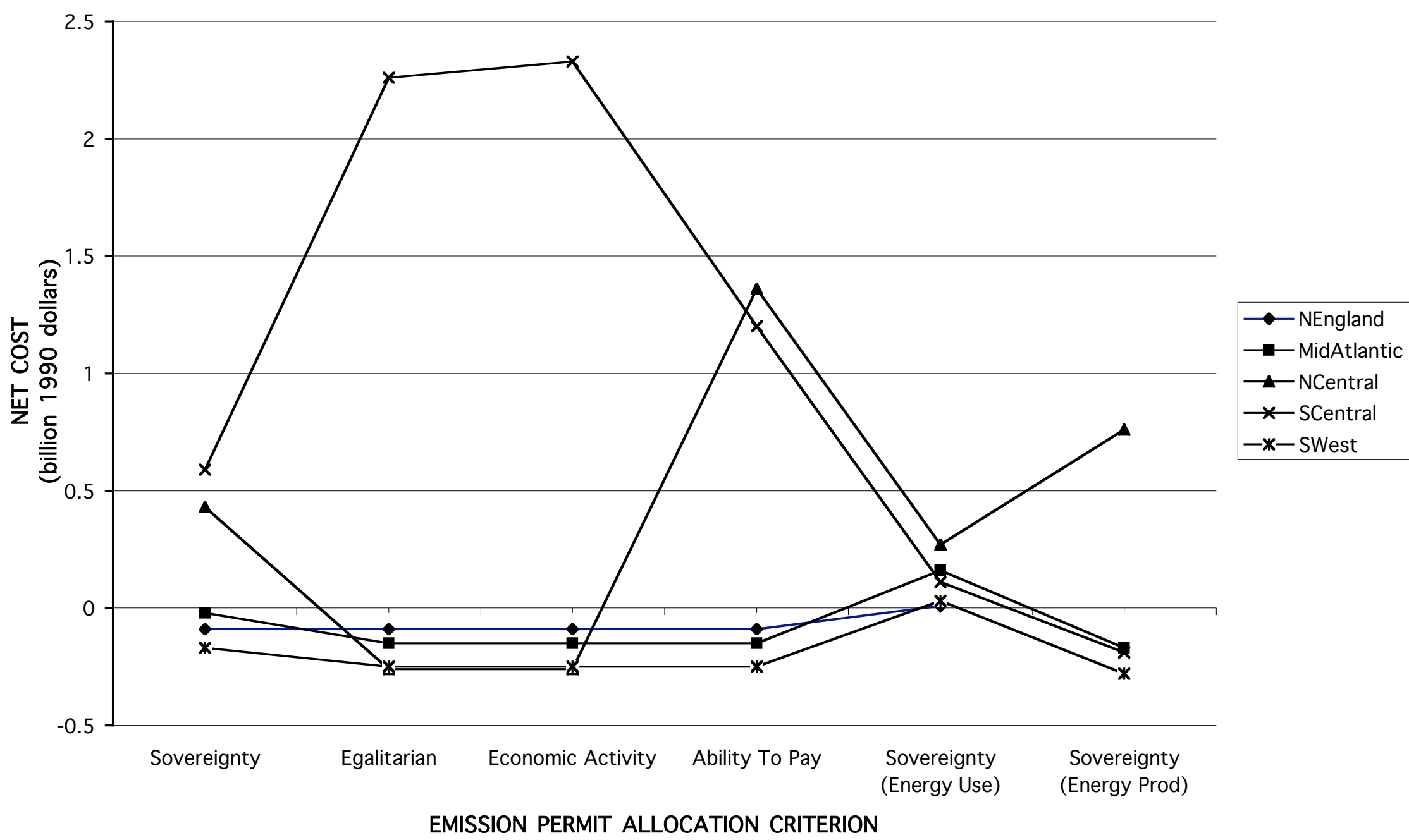

